\title{
New estimates of Arctic and Antarctic sea ice extent during September 1964 from recovered Nimbus I satellite imagery
}

\author{
W. N. Meier, D. Gallaher, and G. G. Campbell \\ National Snow and Ice Data Center, University of Colorado, Boulder, Colorado, USA \\ Correspondence to: W. N. Meier (walt@nsidc.org) \\ Received: 27 November 2012 - Published in The Cryosphere Discuss.: 2 January 2013 \\ Revised: 27 March 2013 - Accepted: 28 March 2013 - Published: 23 April 2013
}

\begin{abstract}
Visible satellite imagery from the 1964 Nimbus I satellite has been recovered, digitized, and processed to estimate Arctic and Antarctic sea ice extent for September 1964. September is the month when the Arctic sea ice reaches its minimum annual extent and the Antarctic sea ice reaches its maximum. Images from a three-week period were manually analyzed to estimate the location of the ice edge and then composited to obtain a hemispheric estimate. Uncertainties were based on limitations in the image analysis and the variation of the ice cover over the three-week period. The 1964 Antarctic extent is higher than estimates from the 1979-present passive microwave record, but is in accord with previous indications of higher extents during the 1960s. The Arctic 1964 extent is near the 1979-2000 average from the passive microwave record, suggesting relatively stable summer extents during the 1960s and 1970s preceding the downward trend since 1979 and particularly the large decrease in the last decade. These early satellite data put the recently observed record into a longer-term context.
\end{abstract}

\section{Introduction}

The decline of Arctic sea ice extent over the past 3+ decades is one of the iconic indicators of climate change, culminating with a record low minimum extent in September 2012. The primary source of these sea ice extent estimates is a series of multi-channel passive microwave radiometers, the Scanning Multichannel Microwave Radiometer (SMMR) aboard the NASA Nimbus-7 platform and a succession of Special Sensor Microwave/Imager (SSM/I) sensors on US Department of Defense Meteorological Satellite Program (DMSP) satellites. Several algorithms, such as the NASA
Team (Cavalieri et al., 1984) and bootstrap (Comiso, 1986), have been developed to derive sea ice concentration and extent from estimated passive microwave brightness temperatures. For sensor transitions, algorithm coefficients are adjusted to provide intercalibration (e.g., Cavalieri et al., 2012) and thus a consistent time series through the multi-channel passive microwave sensor record.

This record, starting in late 1978, has yielded invaluable information on long-term trends and variability in sea ice extent in both the Arctic (Parkinson and Cavalieri, 2008; Comiso and Nishio, 2008) and Antarctic (Cavalieri and Parkinson, 2008; Comiso and Nishio, 2008). The data indicate strong downward trends in all seasons and most regions of the Arctic. In the Antarctic, the situation is more complicated with overall increasing trends in hemispheric sea ice extent, but with large interannual and regional variability.

A limitation of these data is that they extend back only to 1978 . Longer time series are desired to investigate longerterm climate trends and to provide longer records for comparison and inputs into climate models. For example, there are anecdotal indications that Antarctic sea ice extent was larger during the 1960s and the $30 \mathrm{yr}$ increasing trend is a return toward those conditions. In the Arctic, a downward trend is evident, particularly during summer, almost from the beginning of the passive microwave record. Earlier data would put these trends into longer-term context.

There are a few earlier sources of sea ice extent information. A single-channel microwave radiometer flown on Nimbus-5, the Electronically Scanning Microwave Radiometer (ESMR), provides data from 1972-1977. However, the single-channel algorithm is not consistent with the multichannel algorithms, the data are low quality, and there is no overlap to intercalibrate the data with the 1978-present 
record. Cavalieri et al. (2003) produced a total extent time series from the combined ESMR-SMMR-SSM/I record by using operational ice charts from the US National Ice Center (Dedrick et al., 2001) as a "bridge" between ESMR and the SMMR-SSM/I period. The National Ice Center ice chart climatology (NIC, 2009) records weekly sea ice information since 1972 based on human analysis of available satellite imagery and aerial reconnaissance. The Canadian Ice Service also has compiled a climatology of their charts since 1968 for Canadian waters (Tivy et al., 2011). However, particularly during the 1970s, satellite imagery was limited and the ice charts were often based on climatology and the analysts' knowledge of the sea ice environment. Finally, a climatology has been produced from Russian ice charts for Russian waters from the early 1930s (Mahoney et al., 2008).

Another long-term sea ice product has been produced by the UK Hadley Centre (Rayner et al., 2003). This product compiled a record of sea ice since 1870 for input to climate models, based on a climatology compiled by Walsh and Chapman (2001), passive microwave data, and other sources. However, much of the record in the Arctic before 1953 and the Antarctic before 1972 was simply an average climatology. In addition, there is not any overlap between the Walsh and Chapman climatology and the passive microwave record, so a discontinuity exists leading to uncertainty in trends. However, the data set has been used to examine Arctic trends since 1953 (Meier et al., 2007, 2012) and compare with model estimates (Stroeve et al., 2007).

These records provide useful, albeit incomplete, information to supplement the high-quality, multi-channel passive microwave record. Nonetheless, there is the desire to add to and improve these estimates. There was a substantial amount of satellite data collected from the early 1960s through the mid-1970s that are potentially useable, but which have not been available and/or not been sufficiently analyzed to be of use. Here we present data from the Nimbus I satellite that can provide new estimates of Arctic and Antarctic sea ice extent during September 1964. This analysis corroborates and expands upon initial analysis of the Nimbus I imagery analyzed shortly after collection by Predoehl (1966).

\section{Nimbus I satellite data}

The era of visible earth remote sensing began with the launch of the NASA Nimbus I in August 1964. It carried the Advanced Vidicon Camera System (AVCS) and other sensors. Nimbus I operated from 30 August to 19 September 1964. It was followed by Nimbus II (operated from 15 May 196618 January 1969) and Nimbus III (14 April 1969-22 January 1972). Thus, the current sea ice satellite record for 1979present can be extended, at least sporadically, $15 \mathrm{yr}$ further back in time.

These early sensor data were not used extensively, not because of data quality issues, but rather due to limitations of computation power and processing speed and because the idea of collecting climate data was not a focus until later.

Here we analyze data from the Nimbus I AVCS sensor and demonstrate the ability to obtain useful sea ice extent estimates as well as other potential information on the sea ice cover. Nimbus I did not reach its planned orbit altitude of $1100 \mathrm{~km}$ due to a short second-stage burn, resulting in an eccentric $429 \mathrm{~km}$ by $937 \mathrm{~km}$ orbit. The lower orbit resulted in higher spatial resolution data with little overlap between images on each orbit. The AVCS used video technology to collect grayscale, daytime snapshots of the reflected radiance from the earth every $91 \mathrm{~s}$. Picture coverage was $300 \times 1200 \mathrm{~km}$ with a nadir resolution of $0.33 \mathrm{~km}$ at perigee. Picture coverage was $650 \times 3000 \mathrm{~km}$ with a nadir resolution of $0.77 \mathrm{~km}$ at apogee. The AVCS images were transmitted to earth receiving stations as analog TV images, which were then photographed onto $35 \mathrm{~mm}$ film. The presence of clouds limits the ability to observe the sea ice surface with the AVCS, but over the three weeks we were able to produce composites of largely clear-sky images covering most of the Arctic and Antarctic sea ice covered regions.

While the Nimbus I operated for only 3 weeks after launch, the time of operation fortunately coincides with the September minimum sea ice extent in the Arctic and the maximum extent in the Antarctic. This is a time period of particular interest for both hemispheres. In the Arctic, the Nimbus data provide a longer-term context for the dramatic decline in sea ice extent since 1979 observed in multi-channel passive microwave data.

In the Antarctic, September is a period when the intriguing Weddell Sea polynya was prominently seen in early passive microwave satellite data during 1974-1976 and to a lesser degree in 1973 (Martinson et al., 1981). Polynyas are semipersistent areas of open water within the ice pack driven either by persistent winds pushing ice away from a barrier such as land, fast ice, or an ice shelf (latent heat), or by upwelling ocean heat (sensible heat) (Morales Maqueda, et al., 2004). Latent heat polynyas are common features along the Antarctic coast due to persistent off-shore winds coming down off the ice sheet. However, the Weddell Sea polynya was a sensible heat polynya well away from the coast. After being a prominent late winter feature during 1974-1976, it has not been observed to the same degree since. The early Nimbus satellite data have the potential to determine if the polynya existed before 1974 .

\section{Methodology}

\subsection{Recovery and processing of imagery}

The process of creating Arctic and Antarctic extent maps began with recovery of the data by the NASA Goddard Space Flight Center (GSFC). The Nimbus I AVCS data were archived on $35 \mathrm{~mm}$ film rolls. The analog film imagery 

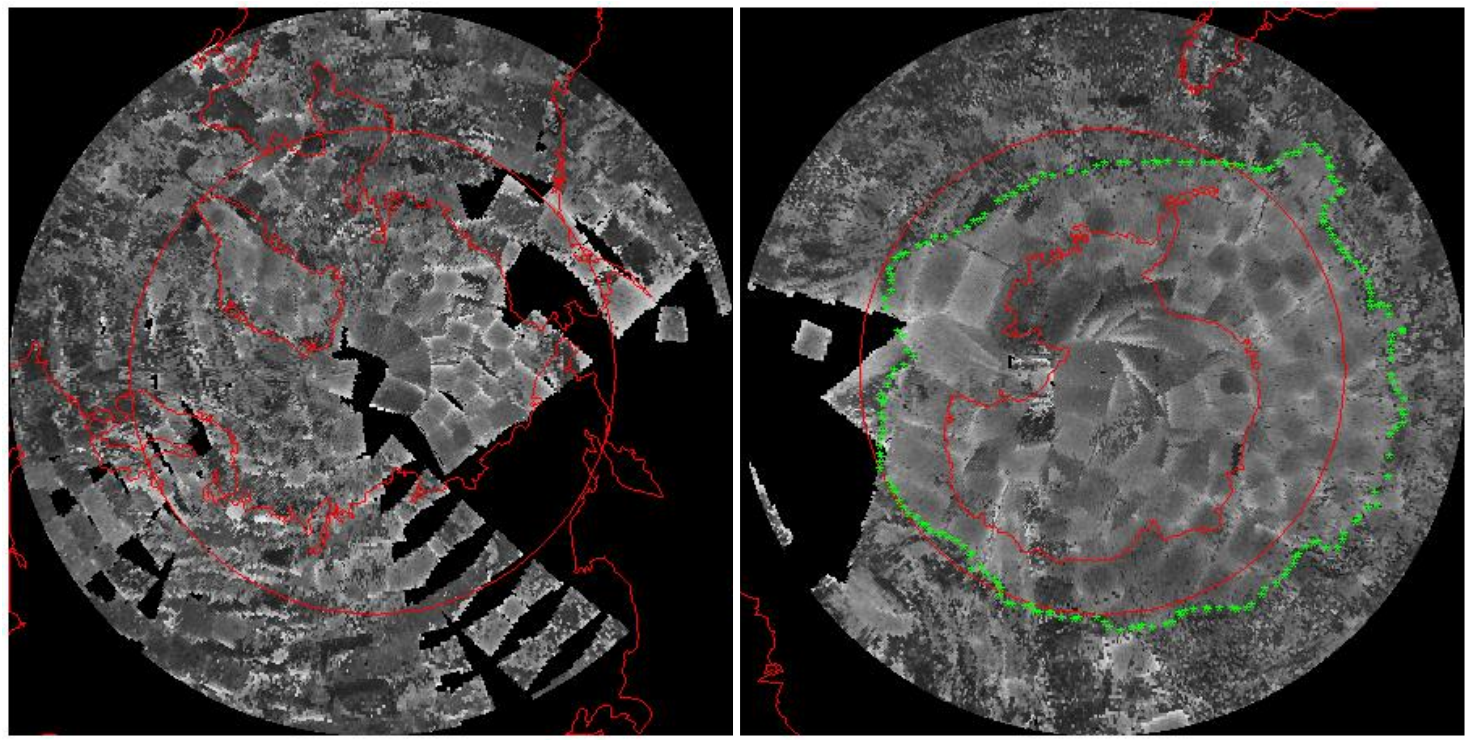

Fig. 1. Composite of Arctic (left) and Antarctic (right) regions from Nimbus I AVCS imagery using a minimum brightness criterion. The red lines show the coastline and the $60^{\circ}$ latitude line. The green line in the Antarctic outlines a possible sea ice boundary based on the automated criterion. In some regions, the brighter sea ice is clearly distinguished from the darker ocean, but there are ambiguities at many locations that make automated delineation of an ice edge difficult.

recorded the black and white output of a video monitor. The effective spectral range of the imagery corresponds to a 4 bit sampling range. Each frame in the film was scanned at an 8 bit sampling range (higher than the 4 bit spectral range of the original film) using a Kodak HR500 high-speed film scanner. Each image was geolocated with the satellite ephemeris data, and a human-augmented custom software application documented each image, recording the time and center points. True north was recorded on each image. This provided navigation accuracy of about $\pm 25 \mathrm{~km}$. Images were checked against known land features. A procedure was implemented to create automated metadata to document the images as they were scanned. Over 13000 images were digitized from Nimbus I.

Although most images have a gray scale to aid in calibration, the camera sensitivity varied during the orbit, making absolute calibration impossible. In addition, the imagery as recorded by the camera corresponds to 4 bit spectral range at best. Thus contrast between high and low reflectance is limited and many fine details (e.g., cloud features) are not evident. However, the imagery is suitable to distinguish between the darker ocean and the lighter ice. And, in general, clouds can be distinguished from the ice cover.

\subsection{Retrieval of ice extent}

Sea ice extent was retrieved by analyzing suitable images near the ice edge. An initial approach composited individual images based on a minimum brightness criterion to filter out cloud-covered images and retrieve a "clear-sky" compos- ite. This provided an initial qualitative indication of the icecovered region (Fig. 1). However, variations in calibration and other ambiguities in the imagery precluded an automated quantitative estimate of the ice edge using this method. Thus, manual visual analysis was used to select the ice edge in individual images.

Images with useful clear-sky regions where an ice edge was visible were analyzed and then composited into the Arctic and Antarctic fields. Overall, roughly 1000 images were reviewed to identify the ice edge boundaries. The composited images covering the ice-covered regions were created from images throughout the three-week period of data acquisition. There are uncertainties in the edge position because of ambiguities in the imagery and limitations of the manual analysis. However, in many regions, an ice edge was quite clear and the position could be established with high confidence (Fig. 2). Another important factor in deriving the ice edge is that imagery was collected over a three-week period. Thus some differences in ice edge location are due to the change in the position of the ice edge during the period of image collection. Thus, the resulting composite is not a snapshot of ice extent, nor does it reflect a true average over the threeweek period. We accounted for regions with uncertainty by marking multiple ice edges - a northern edge and a southern edge. This results in a "bracketing" of the ice extent value and provides a range of uncertainty in the September averages. Nonetheless, the composite ice edges provide a good representation of the spatial distribution of the ice cover and the average location of the ice edge during the sampling period. 


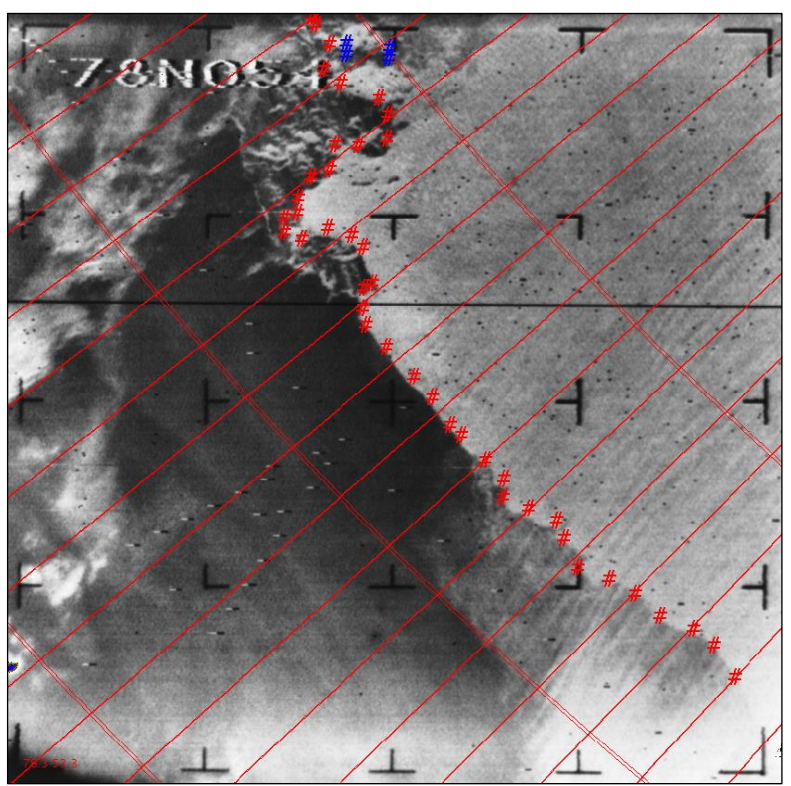

Fig. 2. Sample image of the Arctic ice edge north of Russia near Franz Josef Land (centered at $78^{\circ} \mathrm{N}$ and $54^{\circ} \mathrm{E}$ ) on 4 September 1964. The estimated boundary between the ice and ocean is marked by red "\#" marks; two openings (leads) within the ice are marked by blue "\#” near the ice edge at the top of the image.

\section{Results and evaluation}

\subsection{Antarctic extent}

Near-complete coverage of the Antarctic ice edge was possible over the course of the three weeks of imagery. Our analysis for September 1964 yields a realistic ice edge (Fig. 3) in comparison with passive microwave data, based on the September 1979-2000 median ice edge from the NSIDC Sea Ice Index (Fetterer et al., 2009) (the passive microwave edge location is defined by a $15 \%$ concentration threshold). The bounds between the more northerly and more southerly edge represent multiple views of this area on different days. In some places, such as north of the Weddell Sea, there is little discrepancy in the edge location, indicating a stable and clearly defined ice edge. In other areas, such as in the Indian Ocean sector, there are large discrepancies, indicating ambiguities in the imagery and/or large temporal variation in the ice edge location.

Sea ice extent is calculated by summing the area within (i.e., southward of) the contours and subtracting out the total land, ice sheet, and ice shelf, which are assumed to be an area of $14 \times 10^{6} \mathrm{~km}^{2}$ based on US Geological Survey estimates (Ferrigno et al., 2005). While these may not be totally consistent with the area during the 1960s due to ice shelf changes, the resulting error is not consequential relative to the resolution of the ice edge estimate. The total Antarctic extent for September 1964 is estimated to be $19.7 \times 10^{6} \mathrm{~km}^{2}$, with an

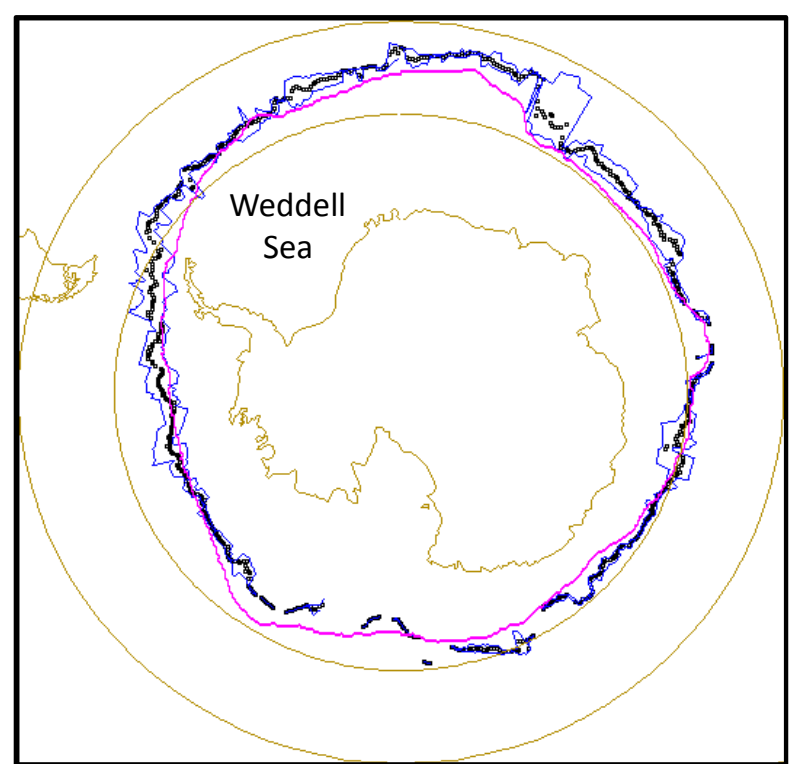

Fig. 3. Outline of Antarctic sea ice edge from Nimbus I AVCS imagery using manual analysis. Solid blue lines represent minimum (more southern) and maximum (more northern) estimates of the ice edge in the manual analysis. Black dots represent the average or "best estimate" of the ice edge. The pink line is the 1979-2000 median ice edge from the passive microwave-based NSIDC Sea Ice Index product.

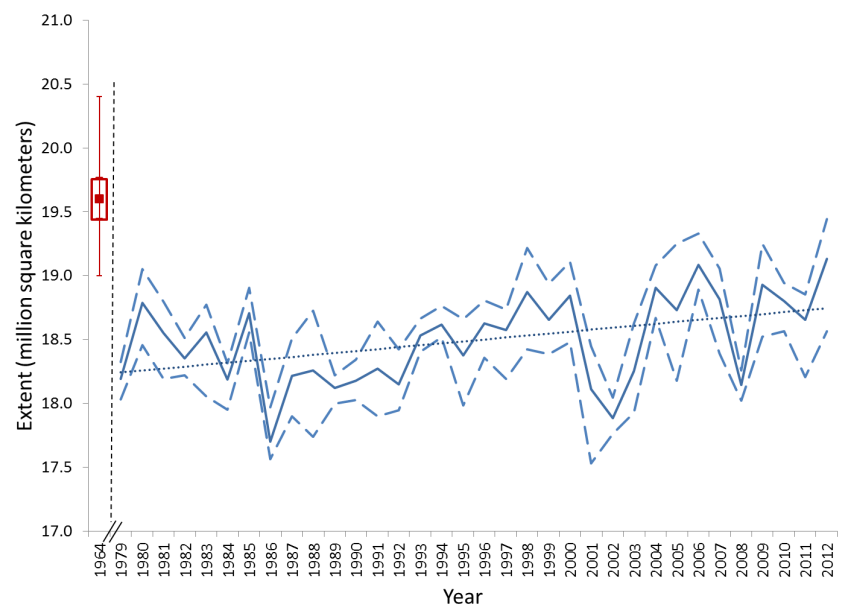

Fig. 4. Time series of Antarctic September sea ice extent. The Nimbus I estimate for 1964 is to the left in red as a box and whisker plot, with the passive microwave NSIDC Sea Ice Index values for 1979-2012 in blue. For Nimbus, the box represents the standard deviation of the different edge locations, while the whiskers represent the absolute maximum and minimum range. The blue solid line is the monthly average passive microwave September values, while the blue dashed lines represent a three-day average of the high and low range of daily extents during the month. 

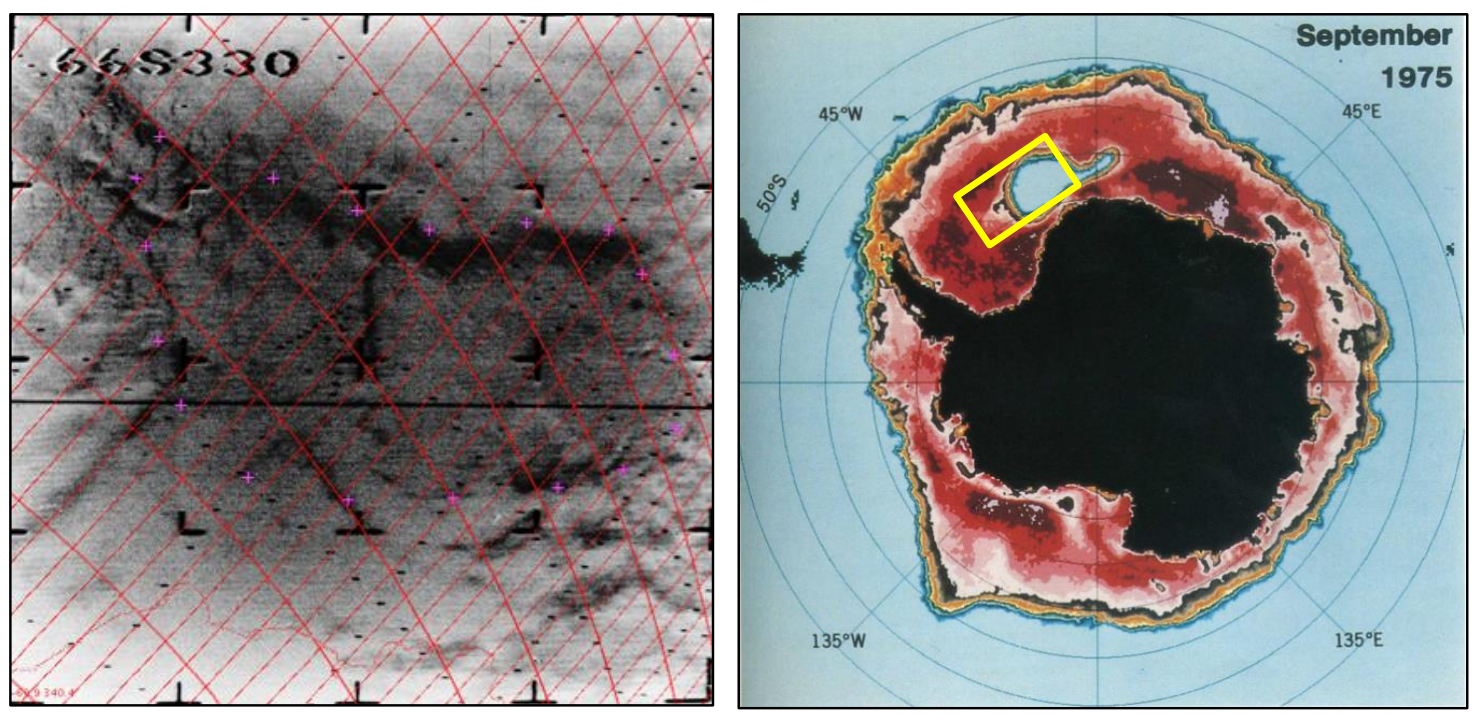

Fig. 5. Nimbus I image from the region of the Weddell Sea polynya $\left(66^{\circ} \mathrm{S}, 330^{\circ} \mathrm{E}\right)$ in September 1964 (left), and the polynya seen in sea ice concentrations derived from passive microwave imagery in September 1975 (right); the yellow square indicates the approximate location of the 1964 scene, which covers an area of roughly $500 \times 2000 \mathrm{~km}$. The dark features in the Nimbus I image indicate potential low ice concentration, and the darkest areas appear to be open water. However, it is not clear if there was a polynya at or near the time of the image or just an indication of leads and clouds.

uncertainty range of 18.9 and $20.4 \times 10^{6} \mathrm{~km}^{2}$ between the northerly and southerly estimates. There are no corroborating ship or aircraft data available to validate our estimate. However, our average estimate is in good agreement with an earlier estimate of $19.81 \times 10^{6} \mathrm{~km}^{2}$ by Predoehl (1966) based on the same imagery.

Notably, our 1964 estimate is substantially higher than the estimates within the passive microwave record (Fig. 4). Even within the wide range of uncertainty in the Nimbus I estimate, the extent is higher than the monthly September average of any of the years of the passive microwave record (1979-2012). Even taking into consideration variation over the month and using the highest and lowest daily extent values during September, the Nimbus I value is clearly on the highest end of the estimates. This suggests that the Antarctic sea ice was more extensive during at least one year in the 1960s, and the small increasing trend during the 1979-2012 period may reflect long-term variability as the ice cover recovers from a relatively low level back to possibly higher 1960s conditions.

As mentioned above, an intriguing feature in early passive microwave imagery is the Weddell Sea polynya that was observed in 1974-1976 and has not been seen to the same degree since. Our analysis of Nimbus I imagery does not show a clear polynya in the region in 1964 . However, there were only 8 views of any given region over the three weeks, and it is difficult to distinguish homogeneous clouds from homogeneous ice within the pack. There is some indication of reduced ice concentration that could be indicative of a polynya feature in some imagery (Fig. 5), but it is not conclusive. Future analy- sis of Nimbus II and III imagery may yield indications of the possible existence of the polynya in those years.

\subsection{Arctic extent}

Determining a September 1964 sea ice extent for the Arctic was more difficult than for the Antarctic. One reason is because of the limited coverage and difficulty in distinguishing the ice edge along the coasts from snow- or glaciercovered islands in the Canadian Archipelago because sea ice contours were drawn along the coastlines during the visual analysis. Another limitation was the lack of data north of Alaska and eastern Siberia because data were downloaded to the Alaska Receiving Station at Fairbanks and simultaneous collection and relaying of data was not possible. The available imagery covered a region extending from the Kara Sea westward across the Barents Sea, Fram Strait, the Canadian Archipelago to the eastern part of the Beaufort Sea. Fortunately, unlike in the Antarctic, there are other sources of extent data that can fill in the gaps in the Nimbus I coverage and provide independent comparison in regions of overlap. We compared our Nimbus I estimates with Russian (AARI, 2007) and Alaskan (NSIDC/WDC, 2005) ice charts (Fig. 6). Where Nimbus I estimates overlap with estimates from the ice charts, there is generally good agreement between the edge of the drifting ice. The Russian ice charts also marked narrow areas of fast ice along the Siberian coast, which we did not include in our estimates.

Combining all three sources, we map the ice edge throughout most of the Arctic Basin, excluding the region between 


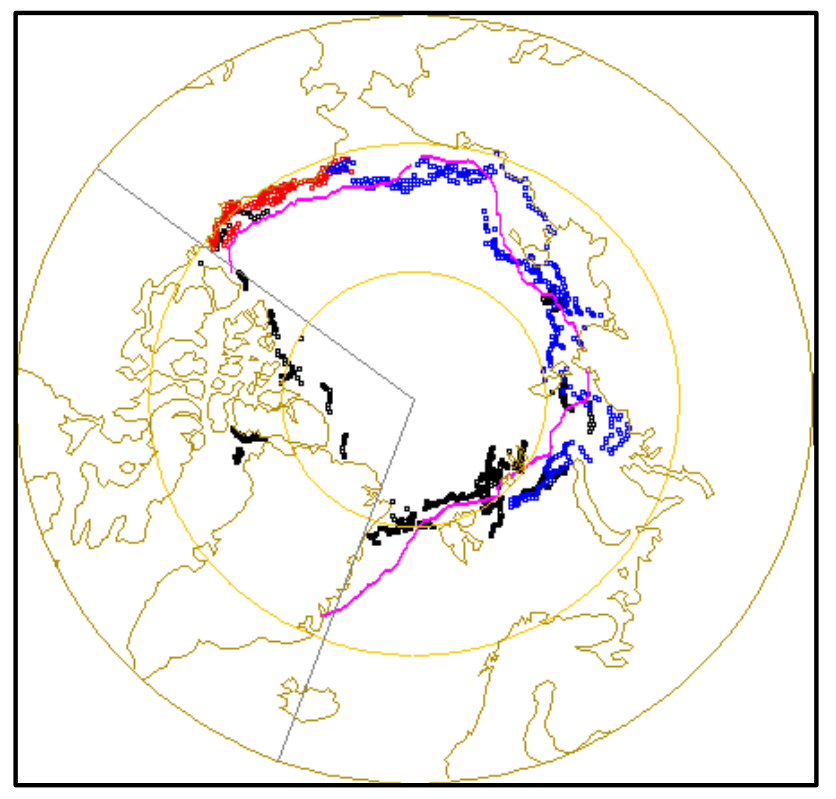

Fig. 6. Outline of September 1964 Arctic sea ice edge from Nimbus I (black dots), Alaskan ice charts (red), and Russian ice charts (blue). The pink line is the 1979-2000 median ice edge from the passive microwave-based NSIDC Sea Ice Index product. The straight gray lines indicate the region filled in by the 1979-2000 average extent from the Sea Ice Index.

$20^{\circ}$ and $127^{\circ} \mathrm{W}$ longitude, primarily encompassing the Canadian Archipelago (because of the lack of useable Nimbus I imagery in that region or ambiguity in the imagery, such as flaw leads near the coast) (Fig. 6). We filled this region with the average of the 1979-2000 extent from the passive microwave record, $1.76 \times 10^{6} \mathrm{~km}^{2}$. Summing the total extent within the Arctic Basin yields an estimate of $6.90 \pm 0.3 \times 10^{6} \mathrm{~km}^{2}$. This compares to a total extent from the average 1979-2000 extent from the Sea Ice Index of $7.04 \times 10^{6} \mathrm{~km}^{2}\left( \pm 0.55 \times 10^{6} \mathrm{~km}^{2}\right.$ st. dev. $)$. Overall then, the 1964 estimate is reasonably consistent with the 1979-2000 conditions, with the 1964 estimate falling within the range of extents during the passive microwave era (Fig. 7). This suggests that September extent in the Arctic may have been generally stable through the 1960s and early 1970s, though more years of data are needed to confirm this. On the other hand, the estimate is considerably lower than from the UK Hadley Centre (Rayner et al., 2003); even after adjustments to be consistent with the passive microwave record (Meier et al., 2012), the extent of $8.28 \times 10^{6} \mathrm{~km}^{2}$ is much higher than the estimate from Nimbus I. This may reflect bias in the Hadley estimates or limitations in the ability to detect the ice edge in Nimbus I imagery.

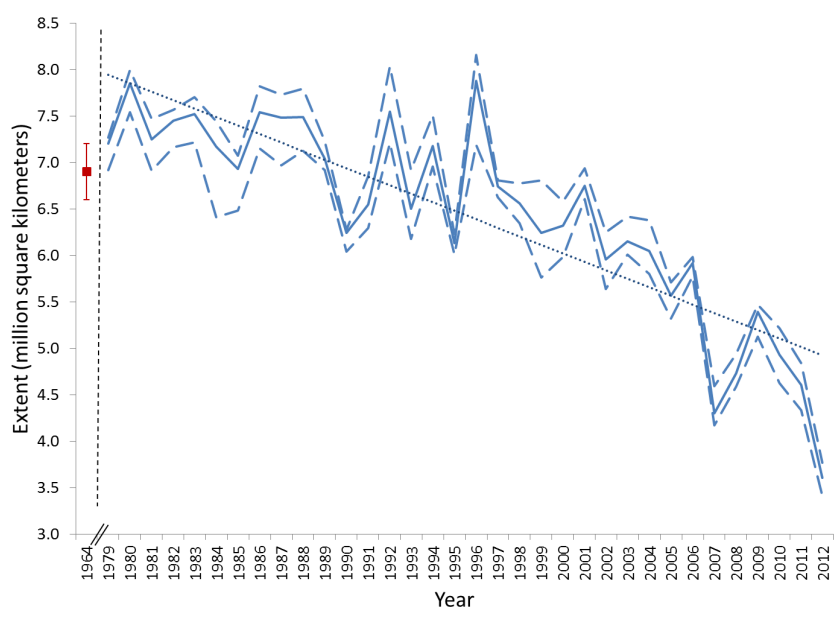

Fig. 7. Time series of Arctic September sea ice extent. The combined estimate for 1964 from the Nimbus imagery and the Russian and Alaskan ice charts is to the left, with the passive microwave NSIDC Sea Ice Index values for 1979-2012 in blue. For Nimbus, the error bars represent the standard deviation of the estimates. The blue solid line is the monthly average passive microwave September values, while the blue dashed lines represent a three-day average of the high and low range of daily extents during the month.

\section{Conclusions}

New maps of the sea ice edge and estimates of total ice extent in the Arctic and Antarctic during September 1964 have been produced from Nimbus I satellite data. Overall, the estimates agree with other data sets and analyses, giving us confidence that our approach yields reasonable estimates that can be extended to other early satellite data. Within our measurement precision, we demonstrate that 1964 Antarctic ice extent is likely higher than any year observed from 1972 to 2012 . We plan to analyze imagery from the subsequent Nimbus II and III satellites as well as other available data from satellites operating in the late 1960s and early 1970s. These have the potential to provide monthly estimates of sea ice extent through much of the period between 1964 and the start of the multi-channel passive microwave era in 1979. This will yield a climate record of sea ice approaching $50 \mathrm{yr}$ in length that will put the recent changes, especially the dramatic decline of Arctic summer sea ice extent, into a longer-term context. These data will also be extremely valuable for validation of climate modeling simulations.

The digitized data used in this study and future research are being documented, compiled into a useable format, and will be archived and distributed by NSIDC. 
Acknowledgements. This research was funded by a sub-contract to NASA grant \#NNG08HZ07C. We also thank the students Carl Gallaher and Alex Calder for their diligence in scanning and documenting the 13000 images used in this study.

Edited by: R. Lindsay

\section{References}

AARI: Sea ice charts of the Russian Arctic in gridded format, 1933-2006, Arctic and Antarctic Research Institute, edited by: Smolyanitsky, V., Borodachev, V., Mahoney, A., Fetterer, F., and Barry, R., Boulder, Colorado USA, National Snow and Ice Data Center, Digital media, 2007.

Cavalieri, D. J. and Parkinson, C. L.: Antarctic sea ice variability and trends, 1979-2006, J. Geophys. Res., 113, C07004, doi:10.1029/2007JC004564, 2008.

Cavalieri, D. J., Gloersen, P., and Campbell, W. J.: Determination of sea ice parameters with the NIMBUS-7 SMMR, J. Geophys. Res., 89, 5355-5369, 1984.

Cavalieri, D. J., Parkinson, C. L., and Vinnikov, K. Y.: 30Year Satellite Record Reveals Contrasting Arctic and Antarctic Decadal Sea Ice Variability, Geophys. Res. Lett., 30, 1720, doi:10.1029/2003GL018031, 2003.

Cavalieri, D., Parkinson, C., DiGirolamo, N., and Ivanov, A.: Intersensor calibration between F13 SSM/I and F17 SSMIS for global sea ice data records, IEEE Geosci. Remote Sens. Lett., 9, 233236, 2012.

Comiso, J. C.: Characteristics of arctic winter sea ice from satellite multispectral microwave observations, J. Geophys. Res., 91, 975-994, 1986.

Comiso, J. C. and Nishio, F.: Trends in the Sea Ice Cover Using Enhanced and Compatible AMSR-E, SSM/I, and SMMR Data, J. Geophys. Res., 113, C02S07, doi:10.1029/2007JC004257, 2008.

Dedrick, K. R., Partington, K., Van Woert, M., Bertoia, C. A., and Benner, D.: U.S. National/Navy Ice Center Digital Sea Ice Data and Climatology, Canad. J. Remote Sens., 27, 457-475, 2001.

Ferrigno, J. G., Williams Jr., R. S., and Fox, A.: Coastal-change and glaciological maps of the Antarctic Peninsula: U.S. Geological Survey Fact Sheet 017-02, 2 pp., available at: http://pubs.usgs. gov/fs/fs17-02/, 2005.

Fetterer, F., Knowles, K., Meier, W., and Savoie, M.: Sea Ice Index, Boulder, Colorado USA: National Snow and Ice Data Center, Digital media, 2002, updated 2009.
Mahoney, A. R., Barry, R. G., Smolyanitsky, V., and Fetterer, F.: Observed sea ice extent in the Russian Arctic, 1933-2006, J. Geophys. Res., 113, C11005, doi:10.1029/2008JC004830, 2008.

Martinson, D. G., Killworth, P. D., and Gordon, A. L.: A convective model for the Weddel!, Polynya, J. Phys. Oceanogr., 11, 466488, 1981.

Morales Maqueda, M. A., Willmott, A. J., and Biggs, N. R. T.: Polynya dynamics: a review of observations and modeling, Rev. Geophys., 42, RG1004, doi:10.1029/2002RG000116, 2004.

Meier, W. N., Stroeve, J., and Fetterer, F.: Whither Arctic sea ice? A clear signal of decline regionally, seasonally and extending beyond the satellite record, Ann. Glaciol., 46, 428-434, 2007.

Meier, W. N., Stroeve, J., Barrett, A., and Fetterer, F.: A simple approach to providing a more consistent Arctic sea ice extent time series from the 1950s to present, The Cryosphere, 6, 13591368, doi:10.5194/tc-6-1359-2012, 2012.

NIC (National Ice Center): National Ice Center Arctic sea ice charts and climatologies in gridded format, edited by: Fetterer, F. and Fowler, C., Boulder, Colorado, USA, National Snow and Ice Data Center, available at: http://dx.doi.org/10.7265/N5X34VDB, 2006, updated 2009.

NSIDC/WDC for Glaciology, Boulder, compiler: The Dehn collection of Arctic sea ice charts, 1953-1986, Boulder, CO, National Snow and Ice Data Center/World Data Center for Glaciology, Digital media, 2005.

Parkinson, C. L. and Cavalieri, D. J.: Arctic sea ice variability and trends, 1979-2006, J. Geophys. Res., 113, C07003, doi:10.1029/2007JC004558, 2008.

Predoehl, M.: Antarctic Pack Ice: Boundaries Established from Nimbus I Pictures, Science, 153, 861-863, 1966.

Rayner, N. A., Parker, D. E., Horton, E. B., Folland, C. K., Alexander, L. V., Rowell, D. P., Kent, E. C., and Kaplan, A.: Global analyses of sea surface temperature, sea ice, and night marine air temperature since the late nineteenth century, J. Geophys. Res., 108, 4407, doi:10.1029/2002JD002670, 2003.

Stroeve, J., Holland, M. M., Meier, W., Scambos, T., and Serreze, M.: Arctic sea ice decline: Faster than forecast, Geophys. Res. Lett., 34, L09501, doi:10.1029/2007GL029703, 2007.

Tivy, A., Howell, S. E. L., Alt, B., McCourt, S., Chagnon, R., Crocker, G., Carrieres, T., and Yackel, J. J.: Trends and variability in summer sea ice cover in the Canadian Arctic based on the Canadian Ice Service Digital Archive, 1960-2008 and 1968-2008, J. Geophys. Res., 116, C03007, doi:10.1029/2009JC005855, 2011.

Walsh, J. E. and Chapman, W. L.: Twentieth-century sea ice variations from observational data, Ann. Glaciol., 33, 444-448, 2001. 